\title{
Editorial: Waste Biorefineries: Future Energy, Green Products and Waste Treatment
}

\author{
Mohammad Rehan ${ }^{1 *}$, Abdul-Sattar Nizami ${ }^{1}$, Umer Rashid ${ }^{2}$ and Muhammad Raza Naqvi ${ }^{3}$ \\ ${ }^{1}$ Centre of Excellence in Environmental Studies (CEES), King Abdulaziz University, Jeddah, Saudi Arabia, ${ }^{2}$ Institute of \\ Advanced Technology, Universiti Putra Malaysia, Seri Kembangan, Malaysia, ${ }^{3}$ Department of Engineering and Chemical \\ Sciences, Karlstad University, Karlstad, Sweden
}

Keywords: waste-to-energy, waste biorefinery, green products, biofuels, bioenergy

\section{Editorial on the Research Topic}

\section{Waste Biorefineries: Future Energy, Green Products and Waste Treatment}

Energy recovery from waste resources holds a significant role in the sustainable waste management hierarchy to support the concept of circular economies and to mitigate the challenges of waste originated problems of sanitation, environment, and public health. Today, waste disposal to landfills is the most widely used methodology, particularly in developing countries, because of limited budgets and lack of efficient infrastructure and facilities to maintain efficient and practical global standards. As a consequence, the dump-sites or non-sanitary landfills have become the significant sources of greenhouse gases emissions, soil and water contamination, unpleasant odors, leachate, and disease spreading vectors, flies, and rodents. However, waste can be a potential source of energy, fuels, and value-added products, if appropriately and wisely managed.

This Frontiers Research Topic was designed to collect new advancements and discoveries on the development of emerging waste-to-energy technologies, practical implementation, and lessons learned from sustainable waste management practices under waste biorefinery concept (Figure 1), which will accelerate the growth of circular economies in the world. This Frontiers Research Topic has attracted and compiled 13 top quality research and review articles. The articles have been written by researchers and academics working in institutions at different countries across the world including Germany, Netherlands, Greece, South Korea, Japan, Hong Kong, Saudi Arabia, Pakistan, Indonesia, Malaysia, Iran, and India. The editorial team of this research topic is very grateful to all the authors for their excellent contributions and making the research topic successful.

Specialty section: This article was submitted to Bioenergy and Biofuels, a section of the journal Frontiers in Energy Research

Received: 04 May 2019

Accepted: 23 May 2019

Published: 12 June 2019

Citation:

Rehan M, Nizami A-S, Rashid U and Naqvi MR (2019) Editorial: Waste

Biorefineries: Future Energy, Green Products and Waste Treatment.

Front. Energy Res. 7:55. doi: 10.3389/fenrg.2019.00055

\section{RESOURCE RECOVERY FROM WASTE}

A wide range of resources, such as energy, fuels, chemicals, and other by-products, can be recovered from waste using different technologies. The article Saghir et al. in this research topic demonstrates how energy deficient countries like Pakistan can generate significant amounts of renewable energy from biomass waste. The authors further discussed the two major classes of the techniques for the processing of biomass into bioenergy, such as (1) thermo-chemical conversion techniques including direct combustion, liquefaction, transesterification, gasification and pyrolysis; and (2) biochemical decomposition techniques including anaerobic decomposition and fermentation.

Biofuels are emerging as alternative clean fuels to replace the fossil fuels that contributed to huge environmental damage and climate change. An interesting study, Akhtar et al. showed the production of biodiesel from non-edible sterculia foetida (Bottle Tree) using $\mathrm{CuO}-\mathrm{CeO}_{2}$ and $\mathrm{Fe}_{2} \mathrm{O}_{3}$ nanocatalysts using transesterification technology. Organic residual streams, such as food waste, 


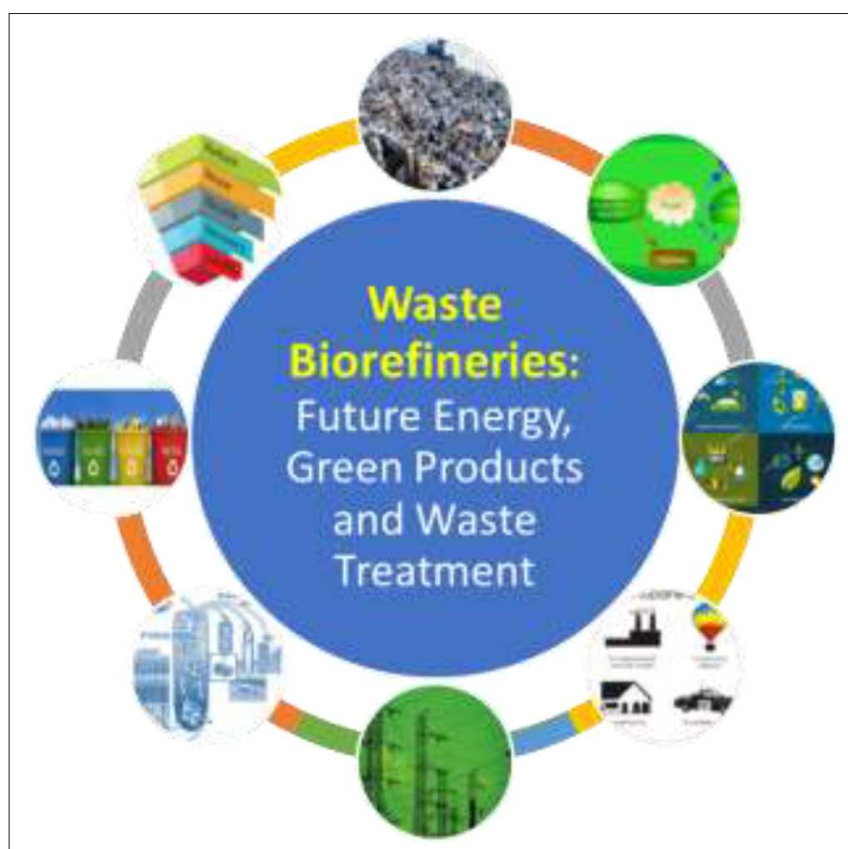

FIGURE 1 | Waste biorefinery concept.

also have great potential as an alternative resource to produce chemicals and fuels, since they are renewable and do not compete with the human food chain. For example, medium chain fatty acids (MCFAs), such as n-caproate, are potential valuable platform chemicals that can be produced from lowgrade organic residues. The study Roghair et al. focused on the production of MCFAs from food waste by anaerobic reactor microbiomes through two subsequent biological processes: hydrolysis combined with acidogenesis and chain elongation. The authors have claimed to set the record for producing the highest concentration of $\mathrm{n}$-caproate $(25.7 \mathrm{~g} / \mathrm{L})$ observed in a chain elongation process to date. Moreover, the study notably demonstrates that such high concentrations can be obtained from food waste under practical circumstances in a continuous process.

\section{WASTE TO ENERGY TECHNOLOGIES}

Energy can be recovered from waste in the form of fuels, heat, and electricity using a wide range of available waste to energy technologies. However, more research and development work is needed to optimize these technologies for achieving maximum economic, environmental and social benefits. A study Prajapati et al. published in this research topic proposed a new method for enhanced methane production from agriculture waste. The same idea can be tested and applied for other wastes such as food waste to produce cleaner biogas for energy applications.

Another study Hanum et al. highlighted the challenges and possible solutions of treating sewage sludge via anaerobic digestion. The authors presented the case study of Malaysia and how the energy can be recovered from huge waste in this country.
The deep understanding of chemistry, thermodynamics, and kinetics of reactions involved in any process is crucial for process control and optimization. A study, Ali and Bahadar presented detailed kinetics of pyrolysis of macro-algae using a simple orderbased model compared with the versatile Šesták-Berggren (SB) model considering combined and multiple reactions.

\section{WASTE BIOREFINERIES}

Waste biorefineries are attracting significant interest worldwide as sustainable waste management solutions as well as facilities to produce fuels, power, heat, and value-added products. This research topic attracted many articles on recent developments and challenges associated with waste biorefineries based on a range of waste. For example, authors have presented detailed experimental data of pyrolysis of plastic waste and way forward to develop pyrolysis based biorefineries using plastic, biomass, and other waste in Miandad et al.. The authors have also discussed the many technical, operational, and socio-economic challenges, and the potential of biorefineries to achieve circular economies.

Other interesting studies published on possibilities of waste biorefineries using waste sludge from water treatment plants (Cheng et al.), used cooking oil (Rahimzadeh et al.), co-digestion of plant biomass and poultry waste (Shah et al.), and co-digestion of catering and agro-industrial waste (Anjum et al.). These studies not only illustrate the possibilities of obtaining different products from a wide range of wastes, but some also showcase studies of corresponding countries.

There could be many ideas and prospects for optimizing waste based biorefineries. For example, the study Wambugu et al. showed the positive role of biochar in food waste based biorefineries. The biochar enhanced the performance of the anaerobic digestion system. The sustainable waste biorefinery facilities represent multifactorial systems that necessitate the organization, cooperation and the acceptance of different social stakeholders. A comprehensive study Kokkinos et al. was published in the research topic in which a novel Fuzzy Cognitive Map (FCM) modeling approach was proposed in order to analyze the socio-economic implications and to overcome multiple uncertainties occurring in sustainable WBF development and implementation.

\section{OUTLOOK}

Waste management in a sustainable and environment-friendly manner is a crucial issue to protect the environment and human health. This research topic highlights the potential and recent developments in waste biorefineries as a sustainable solution to treat waste. Multiple resources such as energy, fuels, chemicals, and other value-added products can be recovered from waste through waste biorefineries. The research topic also highlights the challenges and potential solutions in developing waste based biorefineries from treating different types of waste such as food waste, plastic waste, organic waste, biomass, and agriculture waste. One of the most essential area to work on is to figure out smart ways of integrating different technologies 
under one platform of biorefinery for achieving maximum socioeconomic and environmental benefits.

\section{AUTHOR CONTRIBUTIONS}

MR wrote the initial editorial draft. A-SN critically reviewed and corrected the initial draft. UR and $\mathrm{MN}$ read and approved the final draft. A-SN was responsible for editing 5 chapters, MR: 4 chapters, and MN: 1 chapter, in this research topic.
Conflict of Interest Statement: The authors declare that the research was conducted in the absence of any commercial or financial relationships that could be construed as a potential conflict of interest.

Copyright $\odot 2019$ Rehan, Nizami, Rashid and Naqvi. This is an open-access article distributed under the terms of the Creative Commons Attribution License (CC BY). The use, distribution or reproduction in other forums is permitted, provided the original author(s) and the copyright owner(s) are credited and that the original publication in this journal is cited, in accordance with accepted academic practice. No use, distribution or reproduction is permitted which does not comply with these terms. 